\title{
TET2 suppresses nasopharyngeal carcinoma progression by inhibiting glycolysis metabolism
}

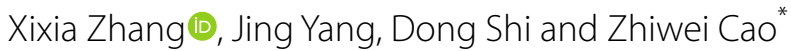

\begin{abstract}
Background: Nasopharyngeal carcinoma (NPC) is a common malignant tumor. Ten-eleven translocation (TET) protein 2 (TET2), an evolutionarily conserved dioxygenases, is reported to be involved in various malignant tumor developments. Here, we aim to investigate the effect of TET2 on NPC progress in vitro and in vivo, and its detailed underlying mechanism.

Methods: Real-time PCR and western blotting were used to determine the expression levels of TET1/2/3 in NPC cell lines. The effects of TET2 on NPC progression were evaluated using CCK8 and invasion assays in vitro. Proteins interacted with TET2 in NPC cells were detected by immunoprecipitation and mass spectrometry. The effects of TET2 or pyruvate kinase, muscle (PKM) on glycolysis in NPC cells were examined by detecting glucose uptake and lactate production. The effects of TET2 on NPC progression were evaluated using xenograft tumor model in vivo.

Results: TET2 expression was decreased in NPC cells, and TET2 overexpression inhibited proliferation and invasion of NPC cells, which is independent on TET2's catalytic activity. In mechanism, TET2 N-terminal domain interacts with PKM in cytoplasm to prevent PKM dimers from translocating into nucleus, suppressing glycolysis in NPC cells, thereby inhibiting proliferation and invasion of NPC cells. Moreover, using xenograft tumor model, we found that TET2 knockout promoted NPC progression and decreased survival rate. However, administration with the inhibitor of PKM, shikonin, decreased the tumor volume of TET2-cas9 group, and increased the survival rate.
\end{abstract}

Conclusion: TET2 suppresses NPC development through interacting with PKM to inhibit glycolysis.

Keywords: Nasopharyngeal carcinoma, Ten-eleven translocation protein 2, Pyruvate kinase, muscle, Glycolysis

\section{Background}

Nasopharyngeal carcinoma (NPC) is characterized by distinct geographical distribution and has a high incidence in southeast Asia and north Africa [1]. Multiple factors, such as Epstein-Barr virus infection, host genetics, and environmental factors contribute to NPC development [2]. Although after radiotherapy and concurrent adjuvant chemotherapy, clinical outcomes of NPC patients have improved, tumor recurrence and distant metastasis are still a tough challenge [3, 4].

*Correspondence: caozwsjh@163.com

Department of Otolaryngology Head and Neck Surgery, Shengjing Hospital of China Medical University, No. 36 Sanhao Road,

Shenyang 110004, Liaoning, China
Therefore, deeply elucidating the detailed mechanism of NPC development is essential for developing novel therapeutic drugs.

Ten-eleven translocation (TET) protein family, including TET1, TET2, and TET3, are evolutionarily conserved dioxygenases, which regulate gene transcription through DNA demethylation via catalyzing the oxidation of 5-methylcytosine (5-mC) to 5-hydroxymethylcytosine $(5-\mathrm{hmC})$, which is generally considered as active sites for gene transcription [5-7]. Recently, emerging studies report that TET2 mutations are closely associated with many tumorous developments, including acute myelocytic leukemia, chronic myelomonocytic leukemia, angioimmunoblastic $\mathrm{T}$ cell lymphoma and mature lymphoid neoplasms [8-10]. Besides, abnormal expression 
of TET2 is reported to be involved in some tumorous progression and drug resistance. For example, increased expression of TET2 promotes melanoma progression by suppressing tumor-infiltrating myeloid cells [11]. Downregulation of TET2 promotes gastric cancer cisplatin resistance via regulating interleukin- 6 expression in the tumor microenvironment [12]. TET2 loss promotes tumorigenesis of breast cancer cells by regulating caspase- 4 [13]. Recent study reports that 5 -hmC level is decreased in metastatic tissues of nasopharyngeal carcinoma, breast cancer, and colon cancer, compared with non-metastasis tumor tissues, and TET2 is involved in the process of tumor metastasis [14]. However, the detailed molecular mechanism of TET2 in NPC progression is still not fully understood.

Hyperactivity of aerobic glycolysis or the Warburg effect is the hallmark of NPC metabolism [15]. Glycolytic metabolism is essential for the perpetual proliferation of tumor cells, and is tightly controlled by various glycolytic enzymes, of which hexokinase (HK), phosphofructokinase (PFK), and pyruvate kinase (PK) are the three pivotally rate-limiting enzymes of glycolysis [16-18]. In mammals, the M2 isoform of pyruvate kinase, muscle (PKM2), which is universally expressed during embryogenesis, regeneration, and cancer, is the last step of glycolysis and catalyzes phosphoenolpyruvate into pyruvate [19]. Then, lactate dehydrogenase (LDH) catalyzes pyruvate to lactate [20]. Most of the enzymes involved in glycolysis have been reported to be overexpressed in tumors, such as lung cancer, hepatocellular carcinoma, and NPC [21-23]. Recently, the 5-mC and 5-hmC modification levels of the genes involved in glycolysis have been reported to differ significantly between hepatocellular carcinoma tissues and paired adjacent peritumor tissues [24]. However, whether TET2 is involved in regulating glycolysis during NPC tumorigenesis is completely unclear.

In the current study, we investigated the expression and biological functions of TET2 in NPC cells and found TET2 plays an inhibitory role on NPC progression. Moreover, we demonstrated that TET2 suppresses NPC progression through interacting with PKM to decrease glycolysis in NPC.

\section{Materials and methods}

\section{Cell culture}

The normal nasopharyngeal cell line NP69,obtained from the Chinese Academy of Science (Beijing, China), was cultured in keratinocyte/serum-free medium (Thermo Fisher) supplemented with bovine pituitary extract (BD Biosciences). Human NPC cell lines CNE1, HNE1, 5-8F, and SUNE-1, obtained from Jiwei Biotechnology (Shanghai, China), were cultured in RPMI-1640 medium supplemented with $10 \%$ fetal bovine serum (FBS) (Gibco) and $1 \%$ penicillin-streptomycin (Gibco). The cells were cultured at $37^{\circ} \mathrm{C}$ with $5 \% \mathrm{CO}_{2}$ in a humidified incubator.

\section{RNA extraction and qRT-PCR}

RNA Extraction and qRT-PCR were performed as previously described [25]. Briefly, cellular RNA was extracted from each sample with the Trizol reagent (Thermo Fisher) and then reverse-transcribed into cDNA using the PrimeScript RT re-agent kit (Takara). QRT-PCR was performed using the 7500 real-time PCR system (Applied Biosystems), with AceQ qPCR SYBR Green Master Mix (Roche). The obtained data were normalized to GAPDH expression levels in each sample. The primers for qRTPCR were as following: TET1 F: 5'-CGCTACGAAGCA CCTCTCTTA-3', TET1 R: 5'-CTTGCATTGGAACCG AATCATTT-3'; TET2 F: 5'-CCCACAGAGACTTGC ACAACAT-3', TET2 R: 5'-CTGGCTCTGCTAACA TCCTGAC-3'; TET3 F: 5'-AGTGTCCGAAAGCCC ATTCAG-3', TET3 R: 5'-GCAAATAGCGCAAGAGAA GGTT-3'; GAPDH F:5'-TCAACAGCAACTCCCACT CTTCCA-3', and GAPDH R: 5'-ACCCTGTTGCTG TAGCCGTATTCA-3', respectively.

\section{siRNAs, plasmids, lentiviruses and drugs}

siRNA targeting TET2 (siR-TET2), siRNA targeting PKM (siR-PKM), and scrambled siRNA (siR-NC) were purchased from GenePharma (Shanghai, China). cDNA encoding full-length human TET2 (2002 amino acids) was cloned into Flag-tagged vector (pCMV-Flag), and the truncated TET2 proteins [N-terminal (residues 1-1127 amino acids), C1-terminal (residues 1128-2002 amino acids), C2-terminal (residues 1399-2002 amino acids), double-strand beta helix domain (DHBS, residues 18682002 amino acids)] were sub-cloned into pCMV-Flag vector; All constructs were confirmed by DNA sequencing. siRNAs $(50 \mathrm{nM})$ or plasmids $(2 \mu \mathrm{g} / \mathrm{ml})$ were transfected using Lipofectamine 3000 (Thermo Fisher Scientific, USA), as previously described [25]. Lentivirus expressing wild type TET2 (Lenti-TET2) or catalytic inactive mutant (H1367Y and D1369A) [26] (Lenti-TET2A) were constructed and purchased from GenePharma (Shanghai, China). The TET2 inhibitor, Dimethyloxallyl glycine (DMOG, $10 \mu \mathrm{M})$ and Bobcat339 (BC339, $80 \mu \mathrm{M})$, the glucose analog 2-deoxyglucose (2-DG, $2 \mathrm{mM}$ ), and ATP (5 mM) were purchased from Selleck (Selleck, USA). The PKM inhibitor, shikonin, was purchased from Sigma (Sigma, USA).

\section{Invasion assay}

Invasion assay was performed, as previously described [25]. After transfection, CNE1 or SUNE1 cells $\left(2 \times 10^{4}\right)$ were seeded in the upper chamber $(8 \mathrm{~mm}$ pore; Millipore) containing FBS-free medium with the 
Matrigel-coated membrane. Subsequently, 10\% FBS was added to the lower chamber as a chemoattractant. After $24 \mathrm{~h}$, cells were fixed with $3 \%$ paraformaldehyde and stained with $0.1 \%$ crystal violet, and counted using the inverted microscope.

\section{Cell proliferation assay}

Cell proliferation assay was performed, as previously described [25]. After transfection, CNE1 or SUNE1 cells were cultured in a 96-well plate (3000 cells/well). Triplicate wells were measured in each group. Cell viability was determined every $24 \mathrm{~h}$. The plate was incubated at $37^{\circ} \mathrm{C}$ for $2 \mathrm{~h}$ after each well was added with $10 \mu \mathrm{l}$ CCK- 8 solution (Dojindo, Japan). Then the spectrophotometric absorbance was measured at $450 \mathrm{~nm}$ for each sample.

\section{Western blot}

After treatments, NPC cells were washed with PBS and then lysed with cell lysis buffer (CST, USA). Whole cell lysates were centrifuged at $14,000 \mathrm{~g}$ for $5 \mathrm{~min}$ at $4{ }^{\circ} \mathrm{C}$ to remove cell debris, and the supernatants were subjected to SDS-PAGE and immunoblotting, as previously described [25]. The following antibodies used in this study were purchased from Abcam (USA): rabbit anti-TET1 (ab191698), rabbit anti-TET2 (ab94580), rabbit anti-TET3 (ab139311), mouse anti-GAPDH (ab8245), rabbit anti-flag (ab1162), rabbit anti-PKM antibody (ab131021), and rabbit anti-Histone H3 antibody (ab176842).

\section{Immunoprecipitation and mass spectrometry}

Immunoprecipitation was performed as previously described [25]. Briefly, after transfection, CNE1 or SUNE1 cells were collected and lysed with lysis buffer (50 mM Tris- $\mathrm{HCl}$ and $0.1 \% \mathrm{~Np}-40, \mathrm{pH} 7.4)$. After centrifugation, the cell lysates were precleared with protein A/G agarose beads (Santa Cruz Biotechnology, USA) and IgG. Subsequently, the samples were incubated with the anti-flag/TET2 antibody or IgG, and protein A/G agarose beads overnight at $4{ }^{\circ} \mathrm{C}$ with continuous rotation. The beads were then washed three times in lysis buffer, and the immunoprecipitation complexes were eluted from protein $\mathrm{A} / \mathrm{G}$ agarose beads by heating at $100{ }^{\circ} \mathrm{C}$ for $5 \mathrm{~min}$. Following centrifugation, the samples were subjected to SDS-PAGE electrophoresis. Then, the gel was stained with the Fast Silver Stain Kit (Beyotime, Shanghai, China), and analyzed by reverse-phase liquid chromatography coupled with tandem mass spectrometry in Huada protein research and development center (Beijing, China). Mass spectrometry peptide sequences and protein identity were determined by matching fragmentation patterns in protein databases using the Mascot software program (Matrix Science, MA). Enzyme specificity was set to partially tryptic with two missed cleavages. Mass tolerance was set to $20 \mathrm{ppm}$ for precursor ions and fragment ions. The database searched was Swiss-Prot (Homo sapiens). Spectral matches were filtered to contain the false-discovery rate to less than $1 \%$ at the peptide level using the target-decoy method by Huada protein research and development center (Beijing, China).

\section{Nuclear and cytoplasmic extraction}

cellular nuclear and cytoplasmic fractions were extracted using NE-PER ${ }^{\mathrm{TM}}$ Nuclear and Cytoplasmic Extraction Reagents (Thermo Scientific, USA), according to the manufacture's instruction.

\section{Dot-blot assay}

Dot-blot assay was performed following previously reported [27]. Briefly, CNE1 cells were cultured in 6-well plate and treated with the TET2 inhibitor, Dimethyloxallyl glycine (DMOG, $100 \mu \mathrm{M}$, Selleck) for $72 \mathrm{~h}$, or Bobcat339 (BC339, $80 \mu \mathrm{M}$, Selleck) for $24 \mathrm{~h}$. DMSO treatment was used as control. Cellular genomic DNA (500 ng) was extracted by the Wizard Genomic DNA Purification Kit (Promega). DNA samples were diluted in TE buffer, denatured in $0.4 \mathrm{M} \mathrm{NaOH} / 10 \mathrm{mM}$ EDTA for $10 \mathrm{~min}$ at $95{ }^{\circ} \mathrm{C}$, neutralized with equal volume of $2 \mathrm{M} \mathrm{NH}_{4} \mathrm{OAc}(\mathrm{pH}$ 7.0), and spotted on a nitrocellulose membrane (pre-wetted in $1 \mathrm{M} \mathrm{NH4OAc,pH} \mathrm{7.0)} \mathrm{in} \mathrm{two-}$ fold serial dilutions using a Bio-Dot Apparatus Assembly (Bio-Rad). The blotted membrane was rinsed briefly in $2 \times \mathrm{SSC}$, air-dried, baked at $80^{\circ} \mathrm{C}$ for two hours, blocked in $5 \%$ non-fat milk for $1 \mathrm{~h}$ at room temperature, and incubated with anti-5hmC (ab106918, Abcam) at $4{ }^{\circ} \mathrm{C}$ overnight. After washing three times, the membrane was incubated with HRP-conjugated anti-rabbit IgG secondary antibody, treated with ECL substrate and developed using film.

\section{CRISPR knockout cell line construction}

For generation of stable cell pools with TET2 knockout, sgRNA designed (http://crisper.mit.edu/) targeting TET2 was synthesized and cloned into cas9/gRNA plasmids. CNE1 cells were transfected with cas9/gRNA plasmids and screened by puromycin (Amresco, OH, USA). TET2 knockout cell clones were identified by western blotting.

\section{mRNA stability}

To measure the effects of TET2 knockout on PKM mRNA stability, normal CNE1 cells and TET2 knockoutCNE1 (TET2-cas9) cells were treated with $5 \mu \mathrm{g} / \mathrm{ml}$ actinomycin D (Act-D, Sigma, USA) for the indicated times. Then, cells were collected, and RNA was isolated for qRTPCR. The mRNA half-life (t1/2) of PKM was calculated using $\ln 2 /$ slope, and GAPDH was used for normalization. 


\section{Chromatin immunoprecipitation (CHIP)}

CHIP was performed using an EZ-Magna ChIP Chromatin Immunoprecipitation Kit (Millipore, USA), as previously described [25]. Briefly, CNE1cells were lysed, and the chromatin was mainly fragmented ranged from $300 \mathrm{bp}$ to $900 \mathrm{bp}$ by prior digestion with micrococcal nuclease and later ultrasonication. DNA/protein complexes were precipitated by overnight incubation with $4 \mu \mathrm{g}$ antibodies against histone $\mathrm{H} 3$ tri-methylated lysine 4 (H3K4me3, ab185637, Abcam), and then incubated with magnetic protein A/G agarose beads for $2 \mathrm{~h}$. After reversal of protein-DNA cross-links, the DNA was purified and then analyzed by qPCR. The primers for ChIP were as following: PKM promoter 0-0.5 k F: 5'-GGGCCAGACTGTTTCCTCTC-3' and R: 5'-CTT TCTCCCAGGGCGACTTT-3'; PKM promoter 0.5-1 k F: $5^{\prime}$-GGAAGGAGAGAAGCTGGGGA-3' and R: 5'-TCCGGCTTAAAGCGGTCATC-3'; PKM promoter 1-1.5 k F: 5'-GCTTTTCCTCTCCCCTGACC-3' and R: 5'-TCAAAGGCAGGGAAGCAGAG-3'; PKM promoter $1.5 \mathrm{k}-2 \mathrm{k}$ F: 5'-CTCTTTTCTGCTGGGGAG GG-3' and R: 5'-GACACCACCATAGCTCCCAC-3'.

\section{Detection of glucose uptake}

Glucose uptake was determined by a Glucose Colorimetric Assay Kit (Biovision, CA), according to the according to the manufacture's instruction. CNE1 or TET2-knockouted CNE1 cells were cultured into 24-well plates and transfected with siR-NC or siR-PKM for $24 \mathrm{~h}$. Then, supernatant of cell culture medium was collected for detection of glucose uptake. Three independent experiments were carried out for each assay.

\section{Detection of lactate production}

Lactate production was determined by a Lactate Colorimetric Assay Kit (Biovision, CA), according to the according to the manufacture's instruction. CNE1 cells were cultured into 24-well plates and transfected with pcmv-flag-TET2 or its mutants for $24 \mathrm{~h}$. Then, supernatant of cell culture medium was collected for detection of lactate production. Three independent experiments were carried out for each assay.

\section{Detection of phosphoenolpyruvate (PEP) production}

PEP production was determined by a PEP Colorimetric Assay Kit (Biovision, CA), according to the according to the manufacture's instruction. CNE1 or TET2-knockouted CNE1 cells were cultured into 24-well plates and transfected with siR-NC or siR-PKM for $24 \mathrm{~h}$. Then, supernatant of cell culture medium was collected for detection of PEP production. Three independent experiments were carried out for each assay.

\section{Detection of $\mathrm{pH}$ value}

$\mathrm{pH}$ value was determined by a Intracellular $\mathrm{pH}$ Assay kit (Abcam, CA), according to the according to the manufacture's instruction. CNE1 or TET2-knockouted CNE1 cells were cultured into 24-well plates and transfected with siR-NC or siR-PKM for $24 \mathrm{~h}$. Then, supernatant of cell culture medium was collected for detection of $\mathrm{PH}$ value. Three independent experiments were carried out for each assay.

\section{Xenograft tumor model}

One hundred and twenty 4-week-old male BALB/c nude mice were divided into 6 groups randomly. Each group was composed of twenty mice. For exploring the effects of TET2 knockout on tumor development, nude mice were subcutaneous injected with $2 \times 10^{6}$ CNE1 cells (control) or TET2 knockouted-CNE1 cells (TET-cas9). Tumor volume (length $\times$ width $^{2} \times 0.5$ ) was recorded every 5 days post-injection. Survival rate of nude mice were recorded everyday as long as 60 days. For exploring the effects of PKM inhibitor, Shikonin, on NPC progress, after the xenografts were established, the tumor-bearing mice (wild type CNE1 group or TET-cas9 group) were intravenous injection with shikonin $(5 \mathrm{mg} / \mathrm{kg}$, SigmaAldrich, USA) for every 2 days, or DMSO. Then tumor volume and survival rate of tumor-bearing mice were recorded. All animal studies were approved by the Animal Ethics Committee of China Medical University and experiments were conducted according to the National Institutes of Health Guide for the Care and Use of Laboratory Animals.

\section{Statistical analysis}

All data are presented as mean \pm standard deviations (SD). Statistical comparison was performed using Student's $\mathrm{t}$-test and $\mathrm{P}<0.05$ was considered statistically significant.

\section{Results}

TET2 inhibits proliferation and invasion of NPC cells

TET protein family are usually considered as tumor suppressors by promoting locus-specific reversal of DNA methylation [13, 28, 29], however, the detailed molecular mechanisms of TET protein family regulating NPC progress are still unclear. In this study, we first examined the mRNA expression levels of TET family genes in NPC cell lines. As shown in Fig. 1a, TET1 and TET3 mRNAs were variously expressed in NPC cells (CNE1, HNE1, 5-8F and SUNE-1) and the immortalized nasopharyngeal cell line NP69. Interestingly, TET2 mRNA expression 

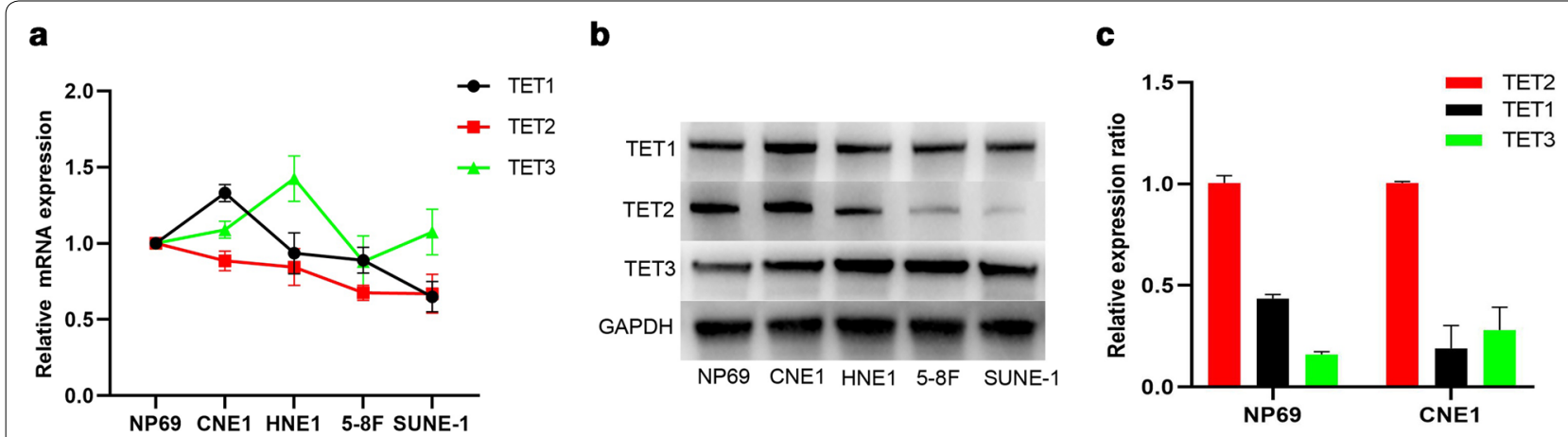

d

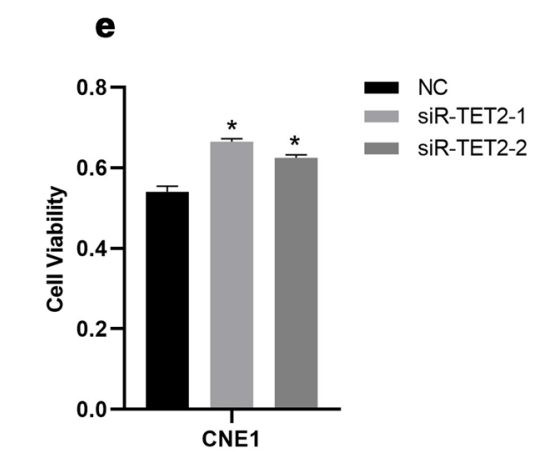

f
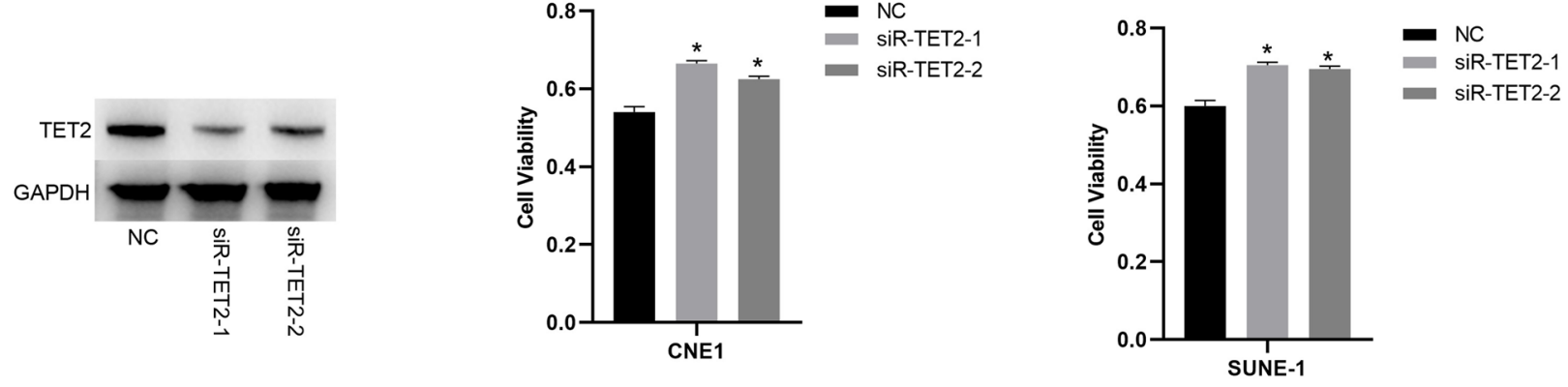

g

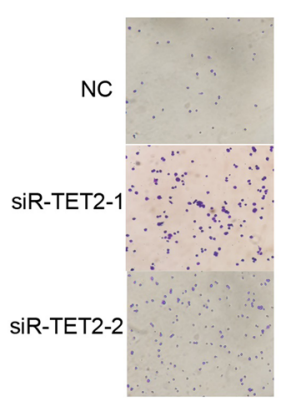

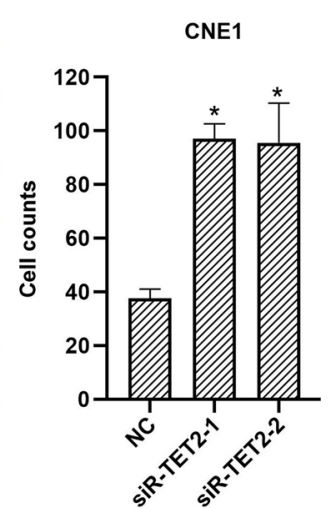

$\mathbf{h}$

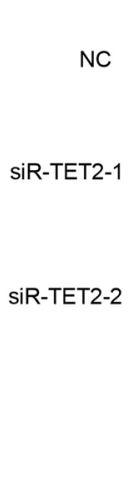

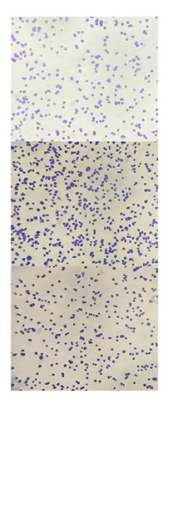

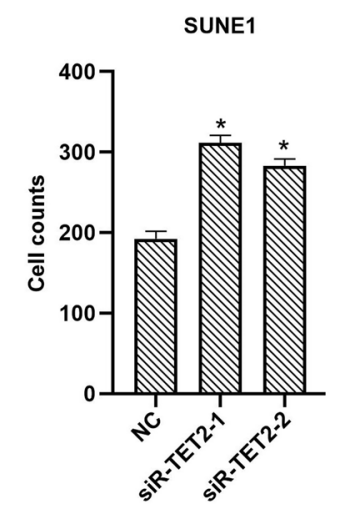

Fig. 1 TET2 inhibits proliferation and invasion of NPC cells. a TET1/2/3 mRNA expression levels were examined in several NPC and the immortalized nasopharyngeal cell line NP69 by qRT-PCR. b TET1/2/3 protein expression levels were examined in the indicated cells by western blotting. $\mathbf{c}$ Relative mRNA expression level of TET1/3 to TET2. d The knockdown efficiency of siR-TET2 was examined by Western blotting in CNE1 cells. Cell viability of TET2-knockdown CNE1 (e) and SUNE1 (f) cells were examined. Cell invasive ability of TET2-knockdown CNE1 (g) and SUNE1 (h) were examined. Data are represented as mean $\pm S D\left(n=3\right.$; ${ }^{*}$ represents $\left.P<0.05\right)$

levels of NPC cell lines were relatively lower that of NP69 cells, and TET2 mRNA expression levels in 5-8F and SUNE-1 cells were lower those in the poorly differentiated CNE1, and HNE1 cells. Consistently, TET2 protein expression levels in HNE1, 5-8F and SUNE-1 cells were also lower that in NP69 cells (Fig. 1b). QPCR analysis of mRNA expression in NP69 and CNE1 cells also showed that TET2 mRNA abundance was higher than TET1 and TET3 (Fig. 1c). Given that TET2 expression level of NPC cells was significantly lower than that of immortalized nasopharyngeal cells, we further explored the roles of TET2 on NPC progress in the following studies. The results showed that TET2 knockdown significantly promoted CNE1 and SUNE-1 cell proliferation (Fig. 1d-f ). Besides, TET2 knockdown also significantly promoted NPC cell invasion (Fig. 1g, h). With above evidence, we 
conclude that TET2 inhibited proliferation and invasion of NPC cells.

\section{TET2 inhibiting proliferation and invasion of NPC cells is independent on TET2's catalytic activity}

To examine whether the demethylated catalytic activity is involved in TET2 promoting proliferation and invasion of NPC cells, we generated TET2-knockout CNE1 cells by CRISPR/Cas9 method (Fig. 2a). Consistent with the results of Fig. 1e, g, TET2 knockout significantly promoted proliferation and invasion of CNE1 cells (Fig. 2b, c). Furthermore, TET2 overexpression mediated by lentivirus significantly inhibited proliferation and invasion of CNE1 cells (Fig. 2d-f ). Besides, overexpression of TET2 mutant with deficiency of catalytic activity also markedly inhibited proliferation and invasion of CNE1 cells, which was comparable to the effects of wild type TET2 overexpression (Fig. 2e, f). Moreover, to confirm the results of Fig. 2e, f, Bobcat339 (BC339), which is a promising cytosine-based TET2 inhibitor [30], and dimethyloxallyl glycine (DMOG), a non-specific 2-OGdependent dioxygenase inhibitor, which not only inhibits TET2's catalytic activity but also decreased TET2 expression [31], were used to inhibit TET2's catalytic activity. As shown in Fig. 2g, h, compared to DMSO treatment, BC339 or DMOG treatment significantly suppressed 5-hmC level of genome in CNE1 cells. Consistent with the results of Fig. 2e, f, BC339 treatment did not affect proliferation and invasion of CNE1 cells, but DMOG treatment markedly increased (Fig. 2i, j). Collectively, our findings indicate that TET2 promoting proliferation and invasion of NPC cells is independent on TET2's catalytic activity.

\section{TET2-PKM interaction is required for TET2 inhibiting proliferation and invasion of NPC cells}

To investigate the molecular mechanism underlying TET2 promoting proliferation and invasion of NPC cells, the proteins interacted with ectopically expressed TET2 (Flag-tagged TET2) in CNE1 cells were immunoprecipitated by anti-Flag antibody and then analyzed by mass spectrometry (Fig. 3a). Among the identified proteins by mass spectrometry (Additional file 1: Table S1), we were interested in pyruvate kinase, muscle (PKM), which is responsible for catalyzing phosphoenolpyruvate into pyruvate in the last step of glycolysis and is highly expressed in bladder cancer and hepatocellular carcinoma $[32,33]$. Subsequently, TET2 interacting with PKM was demonstrated through protein immunoprecipitation in CNE1 and SUNE1 cells (Fig. 3b). Furthermore, ectopically expressed TET2 also interacted with PKM (Fig. 3c).

To investigate the detailed domain of TET2 responsible for binding PKM, different TET2 truncations were constructed. We found that $\mathrm{N}$-terminal domain (residues 1-1127 amino acids) of TET2 is essential for interacting with PKM (Fig. 3d). Moreover, we found that overexpression of full-length TET2 or N-terminal domain of TET2, but not C1-terminal (residues 1128-2002 amino acids), C2-terminal (residues 1399-2002 amino acids) or double-strand beta helix domain (DSBH, residues 1868-2002 amino acids) of TET2, significantly inhibits proliferation and invasion of CNE1 cells (Fig. 3e, f). Whereas, even though overexpression of full-length TET2 or truncated TET2, knockdown of PKM inhibited proliferation and invasion of CNE1 cells (Fig. 3g, h). Taken together, our data demonstrate that TET2-PKM interaction is required for TET2 inhibiting proliferation and invasion of NPC cells.

\section{TET2 interacts with PKM in cytoplasm to prevent PKM dimer formation}

Given that TET2-mediated DNA demethylation acts an essential role in the de novo establishment and maintenance of histone H3K4 trimethylation (H3K4me3)/ H3K27me3 bivalent domains underlying methylated DNA CpG islands [34], and H3K4me3 is generally related to active transcription [35], we further examined whether TET2 interacting with PKM affected PKM gene expression in NPC cells. The result of chromatin immunoprecipitation (CHIP) assay showed that TET2 knockout did not affect H3K4me3 modification on PKM gene promoter (Fig. 4a). Besides, TET2 knockout also did not affect PKM mRNA stability (Fig. 4b). Subsequently, we further investigated whether TET2 affected PKM protein expression. As shown in Fig. 4c, d, ectopically overexpressed wild type TET2 or TET2 mutant with deficiency of catalytic activity did not affect PKM protein expression. Recent study reports PKM dimer regulates the rate-limiting step of glycolysis by transforming glucose metabolism to lactate production [36]. We subsequently analyzed the location of TET2 and PKM interaction. As shown in Fig. 4e, PKM interacted with TET2 primarily distributed in the cytoplasm. In addition, inhibition of the catalytic activity of TET2 by BC339 did not affect PKM dimer formation, but DMOG treatment significantly decreased PKM dimer (Fig. 4f). Collectively, these results indicate that TET2 interacts with PKM in cytoplasm to prevent PKM dimer formation.

\section{TET2 interacting with PKM inhibits proliferation} and invasion of NPC cells by suppressing glycolysis

Whether interaction of TET2 and PKM inhibits PKM dimer-mediated lactate production? Given that PKM is a rate-controlling enzyme of the glycolytic cascade that catalyzes phosphoenol pyruvate (PEP) into pyruvate, which is then catalyzed into lactate by $\operatorname{LDH}[19,20]$. 


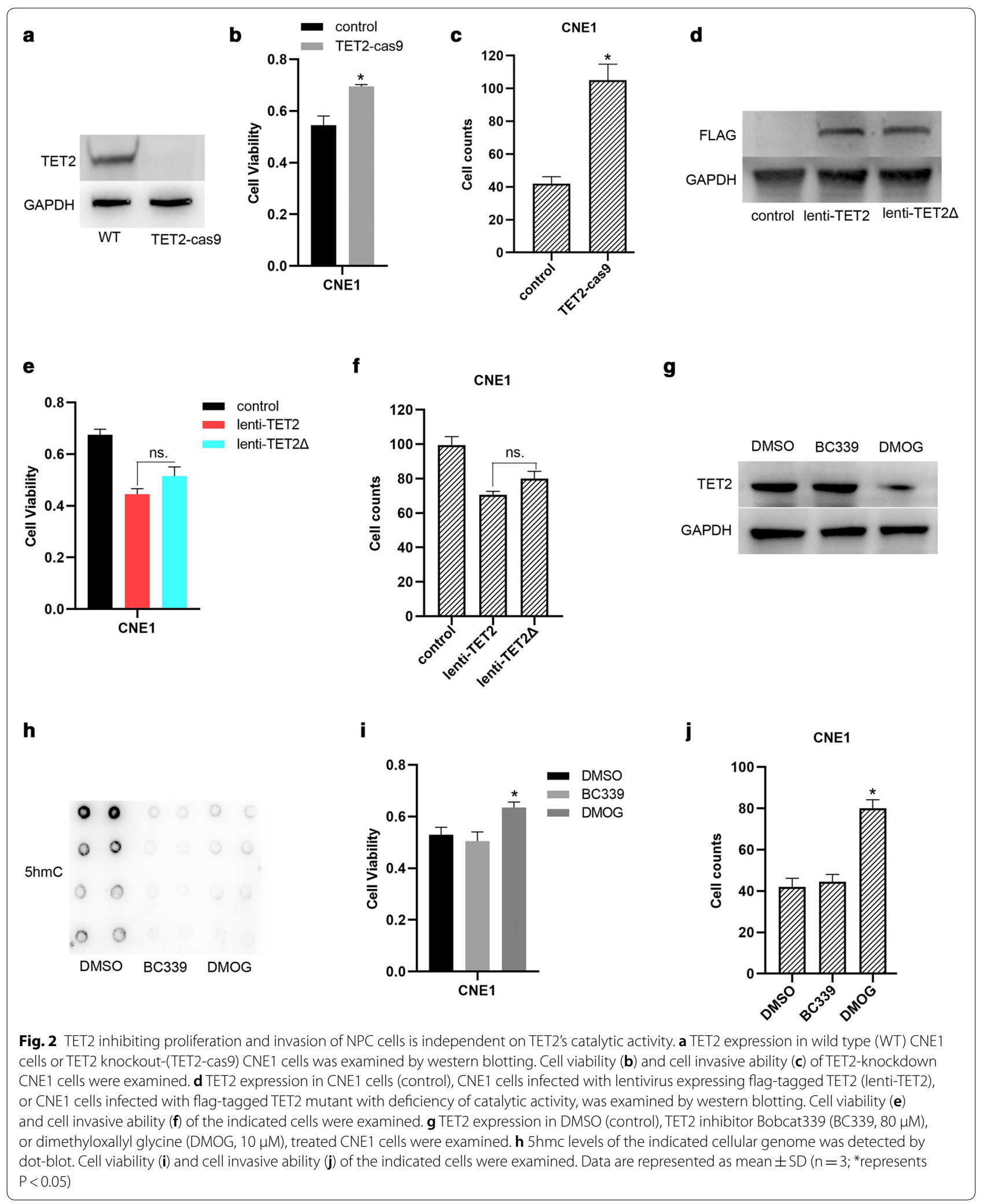




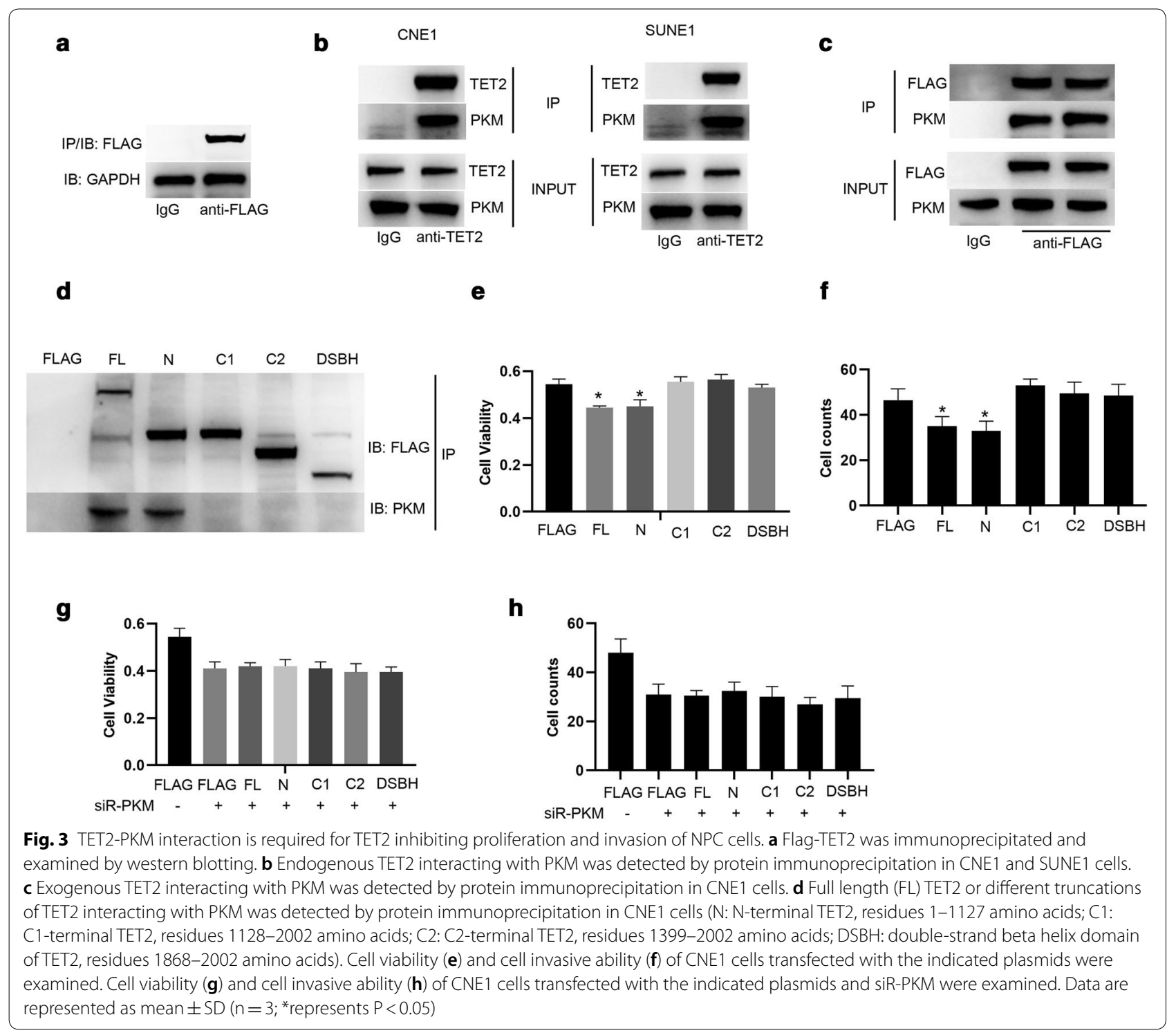

Next, we examined the glycolysis level in NPC cells. As shown in Fig. 5a, TET2 knockout significantly promoted glucose uptake, and decreased intracellular $\mathrm{PH}$ value. Whereas, PKM knockdown markedly reversed the effects of TET2 knockout on glucose uptake and intracellular $\mathrm{PH}$ in CNE1 cells (Fig. 5a). Furthermore, overexpression of wild type TET2 or TET2 mutant with deficiency of catalytic activity significantly suppressed ATP-induced increase in Lactate and PEP production (Fig. 5b). Consistent with that $\mathrm{N}$-terminal domain of TET2 significantly inhibits proliferation and invasion of CNE1 cells (Fig. 3e, f), we also found that TET2 $\mathrm{N}$-terminal domain, but not C1-terminal, C2-terminal or DSBH domain, significantly inhibited ATP-induced
Lactate and PEP production (Fig. 5c). In contrast, TET2 knockout not only increased basal productions of Lactate and PEP, but also significantly promoted ATP-induced Lactate and PEP production (Fig. 5d). Moreover, treatment of shikonin (a specific inhibitor of PKM) markedly suppressed TET2 knockout-induced productions of Lactate and PEP (Fig. 5e), suggesting that TET2 inhibiting glycolysis in NPC cells depends on PKM. In addition, we found that treatment with shikonin or 2-deoxy-D-glucose (2-DG, a well-known inhibitor of glycolysis) significantly suppressed TET2 knockout-induced proliferation and invasion of NPC cells (Fig. 5f, g). Collectively, these results indicate that TET2 interacting with PKM inhibits proliferation and invasion of NPC cells by suppressing glycolysis. 


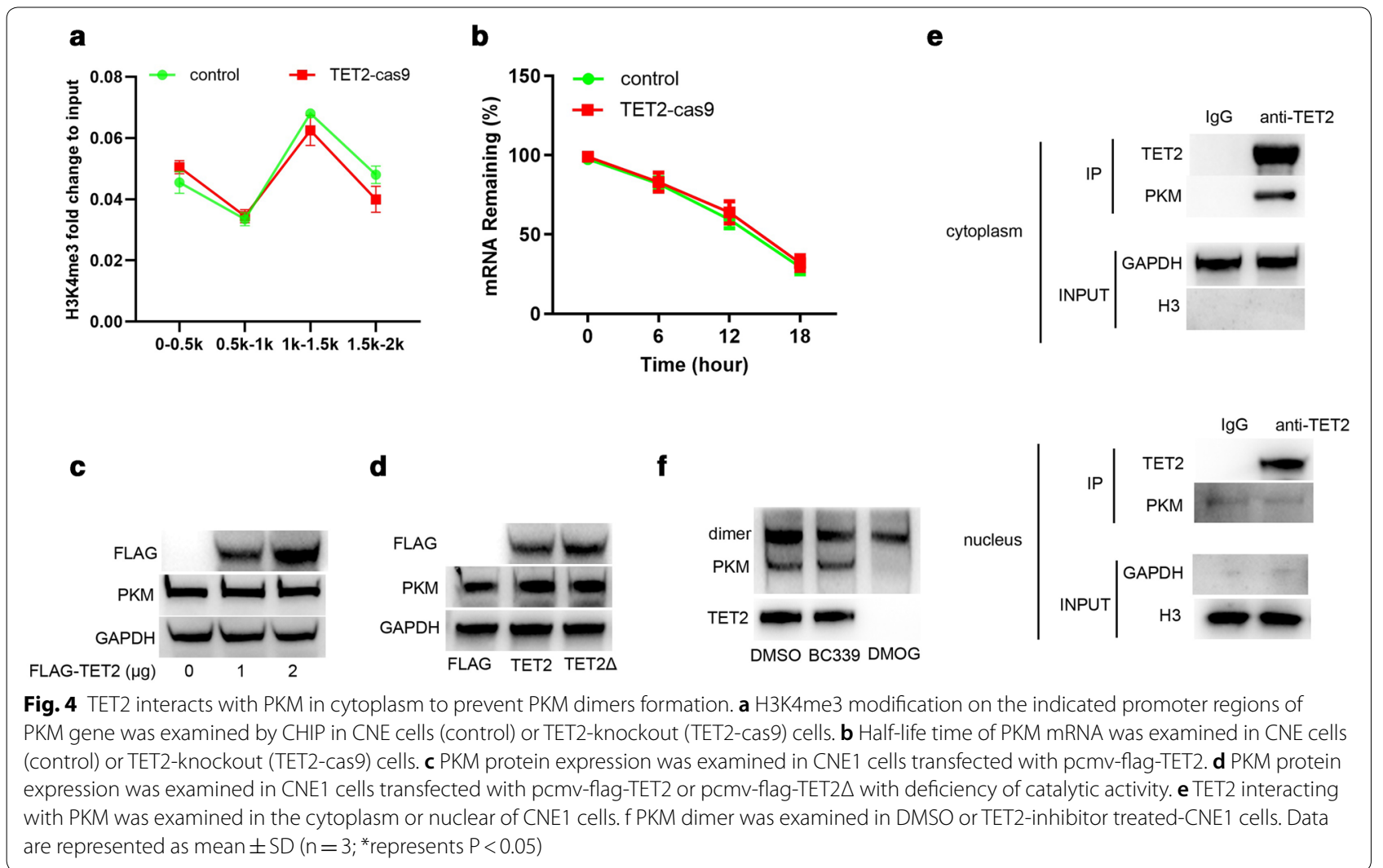

TET2 inhibiting NPC progression in vivo depends on PKM To provide further support for the function of TET2PKM interaction on regulating NPC progress, we subcutaneously injected wild type CNE1 cells (as control), or TET2-knockout (TET2-cas9) cells in nude mice and found that tumor volume increased in TET2-cas9 group, compared with control group (Fig. 6a). Meanwhile, the survival rate of TET2-cas9 group was lower than that of control group (Fig. 6b). Furthermore, we examined the effect of shikonin on tumor growth in vivo. After the xenografts were established, the tumorbearing mice were administered with shikonin $(5 \mathrm{mg} /$ $\mathrm{kg}$ ) via intravenous injection. As shown in Fig. 6c, shikonin treatment inhibited NPC growth and increased the survival rate, compared to PBS (control) (Fig. 6c, d). Moreover, administration with shikonin decreased the tumor volume of TET2-cas9 group, and increased the survival rate, compared to TET2-cas9 group (Fig. 6e, f). Collectively, these results indicate that TET2 inhibiting NPC progress in vivo depends on PKM.

\section{Discussion}

NPC is still a serious health problem with remarkable ethnic and geographic distribution in southern China and Southeast Asia [1]. Recently, epigenetic abnormalities are reported to play important roles in tumor development [37], and TET protein family, which demethylates DNA via catalyzing 5-mC to 5 -hmC, are found to be participated in several tumor pathogenesis [8-14]. However, the roles of TET family in NPC progression are still not well known. In this study, we find that TET 2 protein, but not TET $1 / 3$, is evidently lower expressed in NPC cells, and overexpression of TET2 inhibits NPC development in vivo and in vitro. In mechanism, TET2 interacts with PKM to prevent PKM dimers from translocating into nucleus, thereby suppressing glycolysis and NPC development.

TET2, a DNA methylcytosine dioxygenase, functions as a tumor suppressor in hematopoietic malignancies [8-10]. Many studies report that demethylase activity of TET2 is essential for its tumor inhibitory effect [10-13]. 

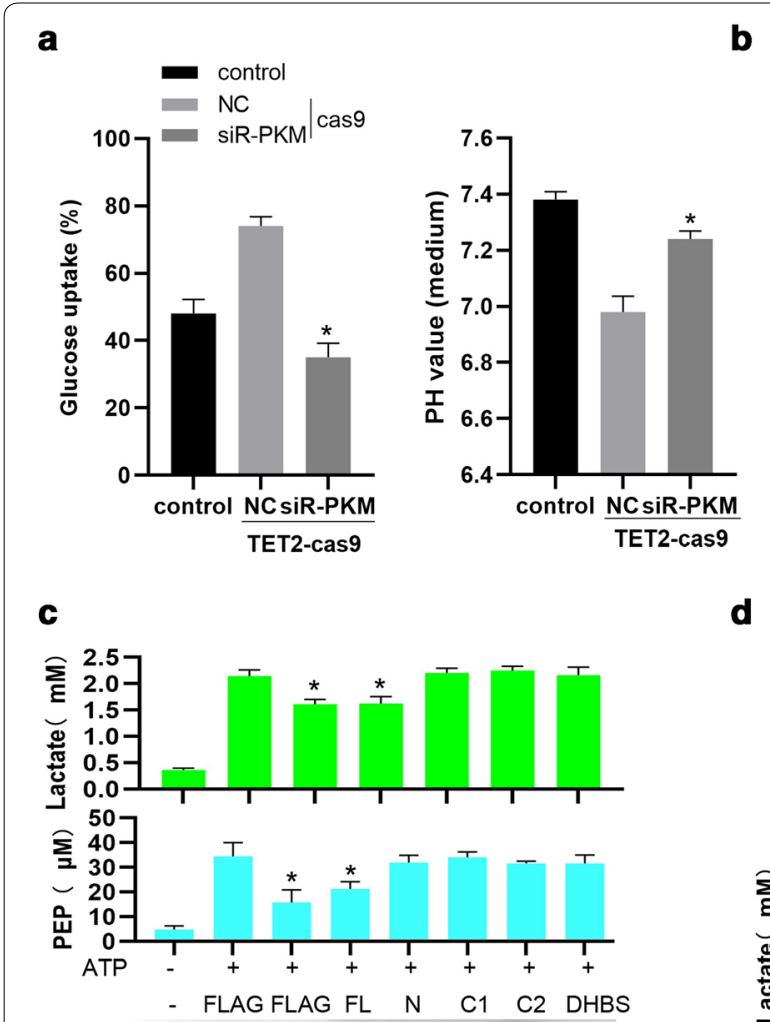

d
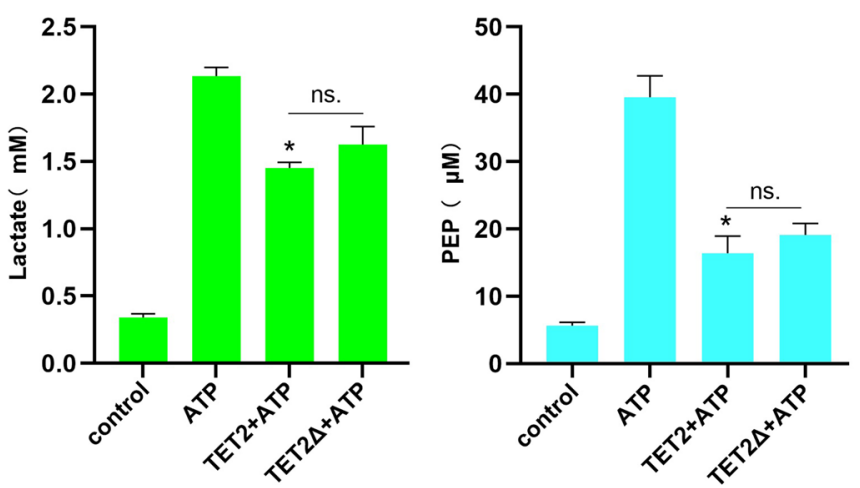

IB: FLAG
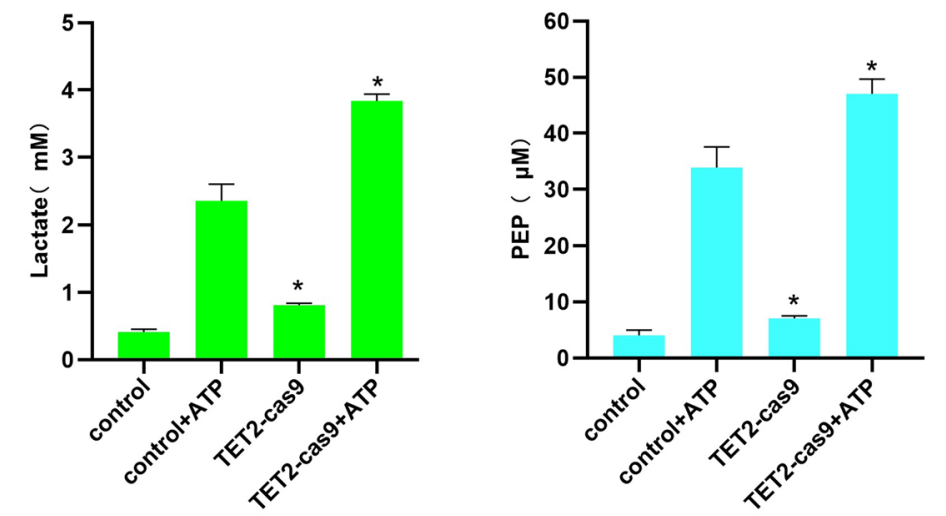

e

$\mathbf{f}$

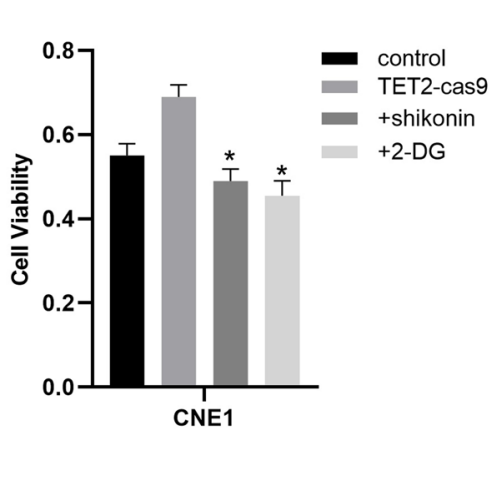

g

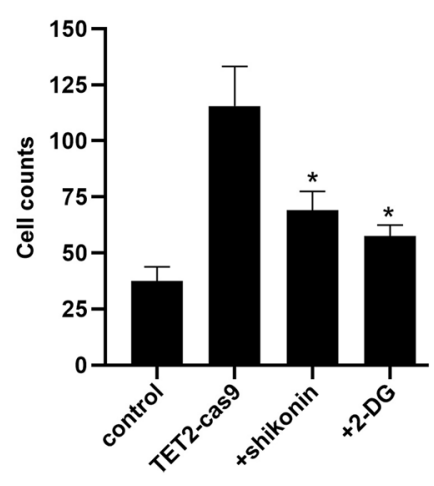

Fig. 5 TET2 interacting with PKM inhibits proliferation and invasion of NPC cells by suppressing glycolysis. a Glucose uptake or intracellular PH value in CNE1 cells (control) or TET2-knockout CNE1 cells (TET2-cas9) transfected with siR-NC (NC) or siR-PKM. b Lactate or PEP production in CNE1 cells (control) or CNE1 cells transfected with pcmv-flag-TET2 or pcmv-flag-TET2 $\triangle$ with deficiency of catalytic activity, and treated with ATP $(100 \mu \mathrm{mol} / \mathrm{L})$ for $24 \mathrm{~h}$ was examined. $\mathbf{c}$ Lactate or PEP production in CNE1 cells (control) or CNE1 cells transfected with the indicated plasmids and treated with ATP $(100 \mu \mathrm{mol} / \mathrm{L})$ for $24 \mathrm{~h}$ was examined. $\mathbf{d}$ Lactate or PEP production in CNE1 cells (control) or TET2-knockout CNE1 cells (TET2-cas9) treated with ATP $(5 \mathrm{mM})$ for $24 \mathrm{~h}$ was examined. e Lactate or PEP production in CNE1 cells (control) or TET2-knockout CNE1 cells (TET2-cas9) treated with PKM inhibitor, shikonin $(10 \mu \mathrm{mol} / \mathrm{L})$ for $24 \mathrm{~h}$ was examined. Cell viability $(\mathbf{f})$ and cell invasive ability $(\mathbf{g})$ of CNE1 cells (control) or TET2-knockout CNE1 cells (TET2-cas9) treated with the PKM inhibitor shikonin (10 $\mu \mathrm{mol} / \mathrm{L})$ or the glucose analog 2-deoxyglucose (2-DG, $5 \mathrm{mM})$ for $24 \mathrm{~h}$ was examined. Data are represented as mean $\pm S D\left(n=3\right.$; ${ }^{*}$ represents $\left.P<0.05\right)$ 

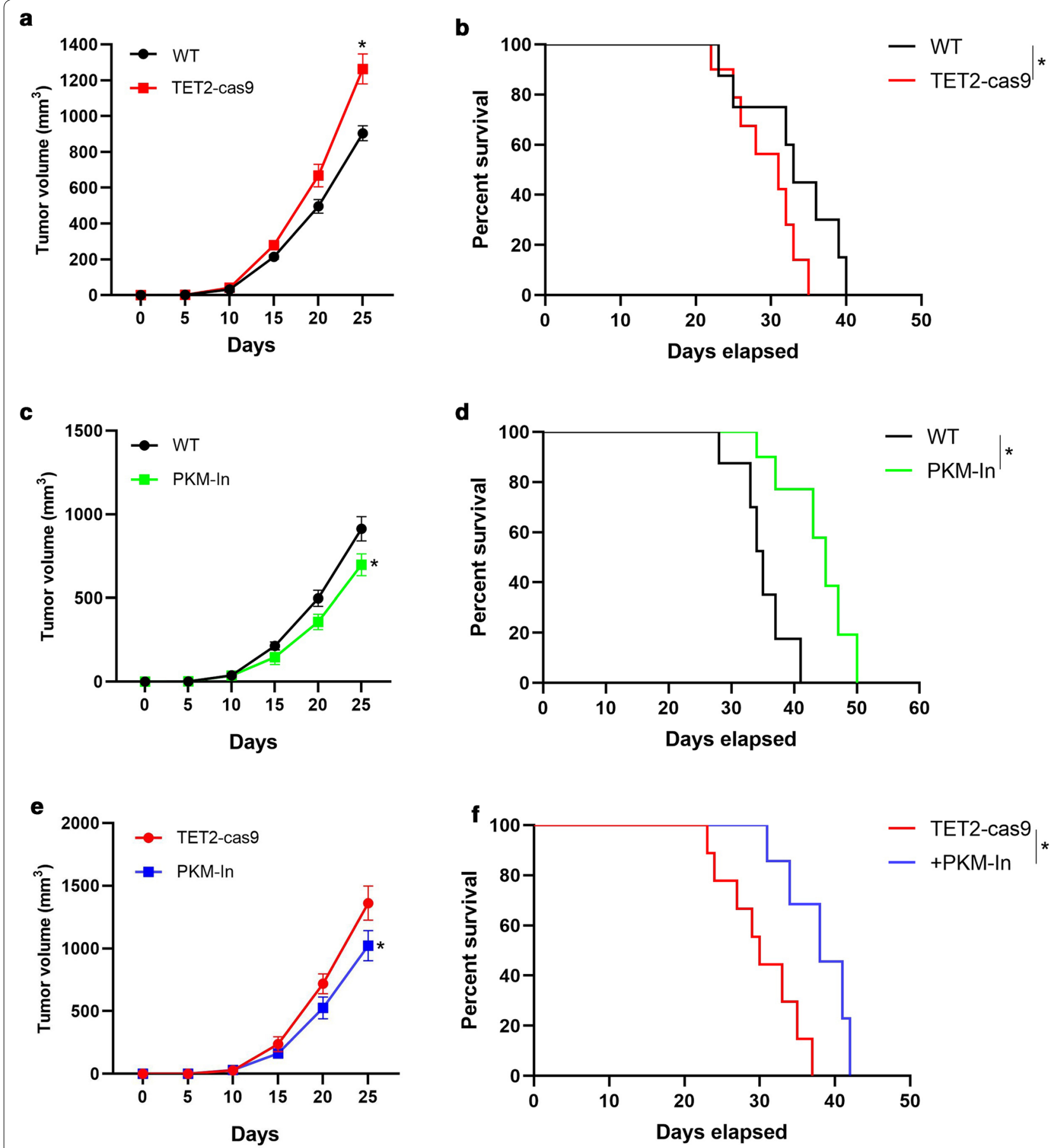

Fig. 6 TET2 inhibiting NPC progress in vivo depends on PKM. a The tumor volume of nude mice with established subcutaneous TET2-WT (control) and TET2-knockout (TET2-cas9) xenografts was recorded. b The survival curve of nude mice with established subcutaneous TET2-WT (control) and TET2-knockout (TET2-cas9) xenografts was calculated. c Nude mice with established subcutaneous TET2-WT xenografts were treated with the PKM inhibitor (PKM-In), shikonin ( $5 \mathrm{mg} / \mathrm{kg}$ ) or PBS for every 2 days. The animals were maintained for post-treatment observation. The tumor volume of nude mice was recorded. $\mathbf{d}$ The survival curve of the indicated nude mice was calculated. e Nude mice with established subcutaneous with TET2-knockout (TET2-cas9) xenografts were treated with the PKM inhibitor (PKM-In), shikonin (5 mg/kg) or PBS for every 2 days. The animals were maintained for post-treatment observation. The tumor volume of nude mice was recorded. $\mathbf{d}$ The survival curve of the indicated nude mice was calculated. Data are represented as mean $\pm S D(n=3$; *represents $P<0.05)$ 
Interestingly, we found that the suppressing effect of TET2 on NPC progression is partly independent on its enzymatic activity. Overexpression of TET2 mutant with deficiency of catalytic activity markedly inhibits proliferation and invasion of CNE1 cells, which is comparable to the effects of TET2 overexpression. Through immunoprecipitation and mass spectrometry analysis, we found that TET2 specifically interacts with PKM to slow down lactate production, which is essential for tumorigenesis [36]. PKM acts as a pivotal role in glucose metabolism, PKM1 and PKM2 are formed by alternative splicing from the same single mRNA transcript [18]. PKM1 was expressed mainly in matured brain tissues and skeletal muscle, while PKM2 was widely expressed in embryonic tissues [38]. During tumor progression, PKM1 mRNA was substituted gradually by PKM2 mRNA transcript to reprogram glycolysis in tumor and PKM2 protein expressed increasingly $[18,39]$. Combined with previous study [15], we speculated TET2 interacts with the PKM2 isoform in nasopharyngeal carcinoma and inhibits PKM2-mediated glycolysis. While PKM1 isoform differs from PKM2 on 389-433 amino acids sequence, whether TET2 interacts with PKM1 and the relative expression ratio of PKM1 and PKM2 in different nasopharyngeal carcinoma cell lines need to be clarified in future.

PKM2 functions by forming highly active enzymatic tetramers, while PKM2 dimer is nearly non-enzymatic activity but possesses transcriptional activity [40]. The ratio of tetrameric form and dimeric form determines whether glucose carbons are channeled to be utilized for glycolytic ATP production or transcriptional activation [41]. In our study, TET2 interacts with PKM suppressing PKM dimer formation. Downregulation of TET2 promotes PKM dimer formation and lactate production, which seems contradictory. Since PKM2 tetramer was constructed from dimer, we speculated whether enhancing the formation of PKM2 dimer induced by TET2 knockdown also promotes PKM2 tetramer, thereby promoting lactate production in NPC. In addition, whether TET2-mediated transcriptional activity deficiency in PKM2 dimer affects NPC invasion also needs to be investigated in our following studies.

Besides PKM2, some other proteins potentially interacted with TET2 in NPC cells, such as PRKAB2 (protein kinase AMP-activated non-catalytic subunit beta 2) and CDK4 (cyclin dependent kinase 4) were identified. PRKAB2, a multi-substrate enzyme activated during metabolic stress caused by exercise, or hypoxia, is involved in regulating energy balance, glycogen metabolism and glycolysis [42], and is usually highly expressed in tumors [43]. CDK4 plays key roles in cell proliferation via driving the progression of cells into the DNA synthetic phase of the cell-division cycle [44], and is involved in the pathogenesis and inducing chemotherapy resistance in NPC $[45,46]$. Whether TET2 inhibiting NPC progression is also associated with PRKAB2/CDK4 needs to be explored in the future studies.

\section{Conclusion}

Our group demonstrates TET2 delays nasopharyngeal carcinoma progression by interacting with PKM and suppressing glycolysis, suggesting that TET2 may serve as a new therapeutic target for NPC.

\section{Supplementary information}

Supplementary information accompanies this paper at https://doi. org/10.1186/s12935-020-01456-9.

Additional file 1: Table S1. Proteins potentially interacted with TET2 identified by mass spectrometry.

\section{Abbreviations}

NPC: Nasopharyngeal carcinoma; TET2: Ten-eleven translocation protein 2; mC: 5-Methylcytosine; 5-hmC: 5-Hydroxymethylcytosine; PKM: Pyruvate kinase, muscle; HK: Hexokinase; PFK: Phosphofructokinase; PK: Pyruvate kinase; LDH: Lactate dehydrogenase; DMOG: Dimethyloxallyl glycine; H3K4me3: Histone H3K4 trimethylation; CHIP: Chromatin immunoprecipitation.

\section{Acknowledgements}

None.

\section{Authors' contributions}

$X Z$, JY, DS and ZC Collection, analysis and interpretation of data, manuscript writing; XZ, JY, DS and ZC collection and interpretation of data; XZ, JY, DS and $\mathrm{ZC}$ conception and design, interpretation of data, manuscript revision. All authors approved the final version of the manuscript. All authors read and approved the final manuscript.

\section{Funding}

This study is supporting by 345 Talent Project of Shengjing Hospital of China Medical University.

\section{Availability of data and materials}

The data in this study are available from the author for correspondence upon reasonable request.

Ethics approval and consent to participate Not applicable.

\section{Consent for publication}

Not applicable.

\section{Competing interests}

There are no conflicts of interest to disclose for all authors.

Received: 26 April 2020 Accepted: 25 July 2020

Published online: 03 August 2020

\section{References}

1. Blanchard P, Nguyen F, Moya-Plana A, Pignon JP, Even C, Bidault F, Temam S, Ruffier A, Tao Y. New developments in the management of nasopharyngeal carcinoma. Cancer Radiother. 2018;22:492-5.

2. Hong M, Tang K, Qian J, Deng H, Zeng M, Zheng S, Ding K, Du Y, Sun R. Immunotherapy for EBV-Associated nasopharyngeal carcinoma. Crit Rev Oncog. 2018;23:219-34 
3. Lu T, Chen Y, Li J, Guo Q, Lin W, Zheng Y, Su Y, Zong J, Lin S, Ye Y, Pan $J$. High soluble programmed death-ligand 1 predicts poor prognosis in patients with nasopharyngeal carcinoma. OncoTargets Ther. 2020;13:1757-65.

4. Huang T, Su N, Zhang X, Ma S, Zhong G, Tian X, Chen Q, Tang L, Lu L, Fang Y, Cai J. Systemic chemotherapy and sequential locoregional radiotherapy in initially metastatic nasopharyngeal carcinoma: Retrospective analysis with 821 cases. Head Neck. 2020. https://doi.org/10.1002/ hed.26130.

5. Wang F, Zhang J, Qi J. Ten-eleven translocation-2 affects the fate of cells and has therapeutic potential in digestive tumors. Chronic Dis Transl Med. 2019;5:267-72.

6. Chapel DB, Husain AN, Krausz T. Immunohistochemical evaluation of nuclear 5-hydroxymethylcytosine (5-hmC) accurately distinguishes malignant pleural mesothelioma from benign mesothelial proliferations. Mod Pathol. 2019;32(3):376-86.

7. Santiago M, Antunes C, Guedes M, Sousa N, Marques CJ. TET enzymes and DNA hydroxymethylation in neural development and functionhow critical are they? Genomics. 2014;104:334-40.

8. Pellissery S, Richter J, Haake A, Montesinos-Rongen M, Deckert M, Siebert R. Somatic mutations altering Tyr641 of EZH2 are rare in primary central nervous system lymphoma. Leukemia Lymphoma. 2010;51:2135-6.

9. Morin RD, Johnson NA, Severson TM, Mungall AJ, An J, Goya R, Paul JE, Boyle M, Woolcock BW, Kuchenbauer F, Yap D, Humphries RK, Griffith OL, Shah S, Zhu H, Kimbara M, Shashkin P, Charlot JF, Tcherpakov M, Corbett R, Tam A, Varhol R, Smailus D, Moksa M, Zhao Y, Delaney A, Qian H, Birol I, Schein J, Moore R, Holt R, Horsman DE, Connors JM, Jones S, Aparicio S, Hirst M, Gascoyne RD, Marra MA. Somatic mutations altering EZH2 (Tyr641) in follicular and diffuse large B-cell lymphomas of germinal-center origin. Nat Genet. 2010;42:181-5.

10. Lessard J, Schumacher A, Thorsteinsdottir U, van Lohuizen M, Magnuson T, Sauvageau G. Functional antagonism of the Polycomb-Group genes eed and Bmi1 in hemopoietic cell proliferation. Genes Dev. 1999;13:2691-703.

11. Pan W, Zhu S, Qu K, Meeth K, Cheng J, He K, Ma H, Liao Y, Wen X, Roden C, Tobiasova Z. The DNA methylcytosine dioxygenase Tet2 sustains immunosuppressive function of tumor-infiltrating myeloid cells to promote melanoma progression. Immunity. 2017;47(2):284-97.

12. Zhou K, Guo H, Zhang J, Zhao D, Zhou Y, Zheng Z, Xu Y, Li Y, Wang D. Potential role of TET2 in gastric cancer cisplatin resistance. Pathol Res Pract. 2019;215:152637.

13. Zhu X, Li S. TET2 inhibits tumorigenesis of breast cancer cells by regulating caspase-4. Sci Rep. 2018;8:16167.

14. Jia J, Shi Y, Chen L, Lai W, Yan B, Jiang Y, Xiao D, Xi S, Cao Y, Liu S, Cheng $Y$, Tao $Y$. Decrease in lymphoid specific helicase and 5-hydroxymethylcytosine is associated with metastasis and genome instability. Theranostics. 2017;7:3920-32.

15. Sung WW, Chen PR, Liao MH, Lee JW. Enhanced aerobic glycolysis of nasopharyngeal carcinoma cells by Epstein-Barr virus latent membrane protein 1. Exp Cell Res. 2017;359:94-100.

16. Tan VP, Miyamoto S. HK2/hexokinase-II integrates glycolysis and autophagy to confer cellular protection. Autophagy. 2015;11:963-4.

17. Sheng H, Tang W. Glycolysis inhibitors for anticancer therapy: a review of recent patents, Recent patents on anti-cancer. Drug Discov. 2016;11(3):297-308.

18. W.J. Israelsen, M.G. Vander Heiden, Pyruvate kinase: Function, regulation and role in cancer, Seminars in cell \& developmental biology 43 (2015) 43-51.

19. Li T, Han J, Jia L, Hu X, Chen L, Wang Y. PKM2 coordinates glycolysis with mitochondrial fusion and oxidative phosphorylation. Protein Cell. 2019;10:583-94.

20. Van Wilpe S, Koornstra R, Den Brok M, De Groot JW, Blank C, De Vries J, Gerritsen W, Mehra N. Lactate dehydrogenase: a marker of diminished antitumor immunity. Oncoimmunology. 2020;9:1731942.

21. Li XB, Gu JD, Zhou QH. Review of aerobic glycolysis and its key enzymes-new targets for lung cancer therapy. Thoracic Cancer. 2015;6:17-24.

22. Ning Z, Tan G. Cancer metabolism: a novel perspective on precision diagnosis and treatment for liver cancer. Zhonghua Wai Ke Za Zhi. 2020;58:31-6.
23. Li X, Lu W, Hu Y, Wen S, Qian C, Wu W, Huang P. Effective inhibition of nasopharyngeal carcinoma in vitro and in vivo by targeting glycolysis with oxamate. Int J Oncol. 2013:43:1710-8.

24. Ye C, Tao R, Cao Q, Zhu D, Wang Y, Wang J, Lu J, Chen E, Li L. Wholegenome DNA methylation and hydroxymethylation profiling for HBVrelated hepatocellular carcinoma. Int J Oncol. 2016;49:589-602.

25. Zhang X, Yang J, Bian Z, Shi D, Cao Z. Long noncoding RNA DANCR promotes nasopharyngeal carcinoma progression by interacting with STAT3, enhancing IL-6/JAK1/STAT3 signaling. Biomed Pharmacother. 2019;1 (113):108713

26. Ito K, Lee J, Chrysanthou S, Zhao Y, Josephs K, Sato H, Teruya-Feldstein J, Zheng D, Dawlaty MM, Ito K. Non-catalytic roles of Tet2 are essential to regulate hematopoietic stem and progenitor cell homeostasis. Cell Rep. 2019;28(10):2480-90

27. Zhang YW, Wang Z, Xie W, Cai Y, Xia L, Easwaran H, Luo J, Yen RC, Li Y, Baylin SB. Acetylation enhances TET2 function in protecting against abnormal DNA methylation during oxidative stress. Mol Cell. 2017;65:323-35.

28. Yu S, Yin Y, Hong S, Cao S, Huang Y, Chen S, Liu Y, Guan H, Zhang Q, Li Y, Xiao H. TET1 is a tumor suppressor that inhibits papillary thyroid carcinoma cell migration and invasion. Int J Endocrinol. 2020;2020:3909610.

29. Carella A, Tejedor JR, Garcia MG, Urdinguio RG, Bayon GF, Sierra M, Lopez V, Garcia-Torano E, Santamarina-Ojeda P, Perez RF, Bigot T, Mangas C, Corte-Torres MD, Saenz-de-Santa-Maria I, Mollejo M, Melendez B, Astudillo A, Chiara MD, Fernandez AF, Fraga MF. Epigenetic downregulation of TET3 reduces genome-wide $5 \mathrm{hmC}$ levels and promotes glioblastoma tumorigenesis. Int J Cancer. 2020;146:373-87.

30. Chua GNL, Wassarman KL, Sun H, Alp JA, Jarczyk El, Kuzio NJ, Bennett MJ, Malachowsky BG, Kruse M, Kennedy AJ. Cytosine-based TET enzyme inhibitors. ACS Med Chem Lett. 2019;10:180-5.

31. Zhang $D, A n X, L i Z$, Zhang S. Role of gene promoter methylation regulated by TETs and DNMTs in the overexpression of HLA-G in MCF-7 cells. Exp Ther Med. 2019;17:4709-14.

32. Zhang $M$, Zhang $H$, Hong $H$, Zhang Z. MiR-374b re-sensitizes hepatocellular carcinoma cells to sorafenib therapy by antagonizing PKM2-mediated glycolysis pathway. Am Journal Cancer Res. 2019;9:765-78.

33. Xie R, Chen X, Chen Z, Huang M, Dong W, Gu P, Zhang J, Zhou Q, Dong W, Han J, Wang X, Li H, Huang J, Lin T. Polypyrimidine tract binding protein 1 promotes lymphatic metastasis and proliferation of bladder cancer via alternative splicing of MEIS2 and PKM. Cancer Lett. 2019;449:31-44.

34. Kong L, Tan L, Lv R, Shi Z, Xiong L, Wu F, Rabidou K, Smith M, He C, Zhang L, Qian Y, Ma D, Lan F, Shi Y, Shi YG. A primary role of TET proteins in establishment and maintenance of De Novo bivalency at $\mathrm{CpG}$ islands. Nucleic Acids Res. 2016;44:8682-92.

35. Santos-Rosa H, Schneider R, Bannister AJ, Sherriff J, Bernstein BE, Emre NC, Schreiber SL, Mellor J, Kouzarides T. Active genes are tri-methylated at K4 of histone H3. Nature. 2002;419:407-11.

36. Zahra K, Dey T, Ashish A, Pandey U, Mishra SP. Pyruvate kinase M2 and cancer: The role of PKM2 in promoting tumorigenesis. Front Oncol. 2020;10:159.

37. Niller HH, Banati F, Salamon D, Minarovits J. Epigenetic alterations in Epstein-Barr virus-associated diseases. Adv Exp Med Biol. 2016;879:39-69.

38. Noguchi T, Inoue H, Tanaka T. The M1- and M2-type isozymes of rat pyruvate kinase are produced from the same gene by alternative RNA splicing. J Biol Chem. 1986;261:13807-12.

39. Prakasam G, Singh RK, lqbal MA, Saini SK, Tiku AB, Bamezai RNK. Pyruvate kinase M knockdown-induced signaling via AMP-activated protein kinase promotes mitochondrial biogenesis, autophagy, and cancer cell survival. J Biol Chem. 2017;292:15561-76.

40. Zhang Z, Deng X, Liu Y, Liu Y, Sun L, Chen F. PKM2, function and expression and regulation. Cell Biosci. 2019;9:52.

41. Lee J, Kim HK, Han YM, Kim J. Pyruvate kinase isozyme type M2 (PKM2) interacts and cooperates with Oct- 4 in regulating transcription. Int J Biochem Cell Biol. 2008;40:1043-54.

42. Dasgupta B, Ju JS, Sasaki Y, Liu X, Jung SR, Higashida K, Lindquist D, Milbrandt J. The AMPK beta2 subunit is required for energy homeostasis during metabolic stress. Mol Cell Biol. 2012;32:2837-48.

43. Ross FA, MacKintosh C, Hardie DG. AMP-activated protein kinase: a cellular energy sensor that comes in 12 flavours. FEBS J. 2016;283:2987-3001.

44. Sherr CJ, Beach D, Shapiro GI. Targeting CDK4 and CDK6: from discovery to therapy. Cancer Discov. 2016;6:353-67. 
45. Liu Z, Cheng C, Luo X, Xia Q, Zhang Y, Long X, Jiang Q, Fang W. CDK4 and miR-15a comprise an abnormal automodulatory feedback loop stimulating the pathogenesis and inducing chemotherapy resistance in nasopharyngeal carcinoma. BMC Cancer. 2016;16:238.

46. Jiang Q, Mai C, Yang H, Wu Q, Hua S, Yan C, Long Y, Zhang Y, Long X, Fang W, Liu Z. Nuclear expression of CDK4 correlates with disease progression and poor prognosis in human nasopharyngeal carcinoma. Histopathology. 2014;64:722-30.

\section{Publisher's Note}

Springer Nature remains neutral with regard to jurisdictional claims in published maps and institutional affiliations.
Ready to submit your research? Choose BMC and benefit from:

- fast, convenient online submission

- thorough peer review by experienced researchers in your field

- rapid publication on acceptance

- support for research data, including large and complex data types

- gold Open Access which fosters wider collaboration and increased citations

- maximum visibility for your research: over $100 \mathrm{M}$ website views per year

At BMC, research is always in progress.

Learn more biomedcentral.com/submissions 